Pacific Journal of Mathematics

A GENERAL THEOREM FOR BILINEAR GENERATING S. SARAN 


\section{A GENERAL THEOREM FOR BILINEAR GENERATING FUNCTIONS}

\section{S. SARAN}

The following theorem was proved by Chatterjea for ultraspherical polynomials:

$$
\text { If } F(x, t)=\sum_{m=0}^{\infty} a_{m} t^{m} P_{m}^{\lambda}(x)
$$

then

$$
\bar{\rho}^{2 \lambda} F\left(\frac{x-t}{\rho}, \frac{t y}{\rho}\right)=\sum_{r=0}^{\infty} t^{r} b_{r}(y) P_{r}^{2}(x)
$$

where

$$
b_{r}(y)=\sum_{m=0}^{\infty}\left(v_{m}\right) a_{m} y^{m} \text { and } \rho=\left(1-2 x t+t^{2}\right)^{1 / 2} .
$$

The object of this paper is to show that a general theorem for any polynomial satisfying certain conditions can be given so as to include the above case, and may be applicable in obtaining new generating functions for other polynomials also.

THEOREM. If

$$
f_{n}(x)=\mu(n) G(x) D^{n}\{g(x)\}
$$

where $g(x)$ and $G(x)$ are independent of $n$, and

$$
F(x, t)=\sum_{m=0}^{\infty} a_{m} t^{m} f_{m}(x)
$$

then

$$
\frac{G(x) F(x-t, t y)}{G(x-t)}=\sum_{r=0}^{\infty} \frac{(-t)^{r}}{\mu(r) r !} b_{r}(y) f_{r}(x)
$$

where

$$
b_{r}(y)=\sum_{m=0}^{r}(-r)_{m} \mu(m) a_{m} y^{m} .
$$

2. Proof of the theorem. Writing $t y$ for $t$ in (1.2) and using (1.1) we get

$$
[G(x)]^{-1} F(x, t y)=\sum_{m=0}^{\infty} a_{m} t^{m} y^{m} \mu(m) D^{m}[g(x)] .
$$

Applying the operator $\bar{e}^{t D}$ where $D \equiv d / d x$ on both sides, we get, since

$$
\bar{e}^{t D} f(x)=f(x-t)
$$




$$
\begin{aligned}
\frac{F(x-t, t y)}{G(x-t)} & =\sum_{m=0}^{\infty} a_{m} t^{m} y^{m} \mu(m) \bar{e}^{t D} D^{m}[g(x)] \\
& =\sum_{m=0}^{\infty} a_{m} t^{m} y^{m} \mu(m) \sum_{r=0}^{\infty} \frac{(-t D)^{r}}{r !} D^{m}[g(x)] \\
& =\sum_{m=0}^{\infty} a_{m} y^{m} \mu(m) \sum_{r=0}^{\infty} \frac{(-)^{r} t^{m+r}}{r !} D^{m+r}[g(x)] \\
& =\sum_{r=0}^{\infty} \frac{(-)^{r} t^{r}}{r !} D^{r}[g(x)] \sum_{r=0}^{m}(-r)_{m} a_{m} \mu(m) y^{m}
\end{aligned}
$$

This on using (1.1) proves the theorem.

3. Some applications of theorem. (i) First we consider the generating function given by Brafman

$$
(1-2 x t)^{-C}{ }_{2} F_{0}\left(\frac{1}{2} C, \frac{1}{2} C+\frac{1}{2},-: \frac{-4 t^{2}}{(1-2 x t)^{2}}\right) \cong \sum_{n=0}^{\infty} \frac{(c)_{n} H_{n}(x) t^{n}}{n !} .
$$

If we take $(a)_{m}=(c)_{m} / m !, f_{m}(x)=H_{m}(x), G(x)=\exp \left(x^{2}\right), \mu(n)=(-)^{n}$ from Rodrigues formula [5] we obtain

$$
\begin{aligned}
& {[1+2 y t(x-t)]^{-c} \exp \left(2 x t-t^{2}\right)_{2} F_{0}\left(\frac{1}{2} c, \frac{1}{2} c+1,-: \frac{-4 y^{2} t^{2}}{\left(1+2 x y t-2 y t^{2}\right)^{2}}\right)} \\
& \quad \cong \sum_{n=0}^{\infty} \frac{{ }_{2} F_{0}(-n, c,-: y) H_{n}(x) t^{n}}{n !},
\end{aligned}
$$

a relation proved by Brafman [1] and Rainville [5] in different ways. [2]

(ii) We now consider the generating function given by Carlitz

$$
\left[1+\frac{1}{2}(x+1) t\right]^{\alpha}\left[1+\frac{1}{2}(x-1) t\right]^{\beta}=\sum_{n=0}^{\infty} P_{n}^{\alpha-n, \beta-n}(x) t^{n} .
$$

Writing $t z$ for $t$, multiplying both sides by $\bar{e}^{z} z^{c-1}$ and integrating w.r.t. $z$ we get

$$
\begin{aligned}
& \sum_{n=0}^{\infty}(c)_{n} P_{n}^{\alpha-n, \beta-n}(x) t^{n} \\
= & \sum_{n=0}^{\infty} \sum_{m=0}^{\infty} \frac{(-\alpha)_{m}(-\beta)_{n}(c)_{m+n}}{m ! n !}\left[\frac{1}{2}(x+1) t\right]^{m}\left[\frac{1}{2}(x-1) t\right]^{n} .
\end{aligned}
$$

Similarly, writing $t / p$ for $t$, multiplying both sides by $e^{p} p^{-D} / 2 \pi i$ and evaluating over the contour $C$ given by Hankel [4] we get

$$
\begin{aligned}
& F^{(1)}\left(c, D ;-\alpha,-\beta: \frac{1}{2}(x+1) t, \frac{1}{2}(x-1) t\right) \\
= & \sum_{n=0}^{\infty} \frac{(c)_{n}}{(D)_{n}} P_{n}^{\alpha-n, \beta-n}(x) t^{n},
\end{aligned}
$$

where $F^{(1)}$ is Appell's hypergeometric function of the first kind [5] 
defined by

$$
F^{(1)}(a, b ; c, d: x, y)=\sum_{m=0}^{\infty} \sum_{n=0}^{\infty} \frac{(a)_{m+n}(c)_{m}(d)_{n}}{(b)_{m+n} m ! n !} x^{m} y^{n} \quad|x|<1,|y|<1 .
$$

Assuming that $f_{n}^{\alpha-n, \beta-n}(x)=\left(1 /\left(1-x^{2}\right)\right) p_{n}^{\alpha-n, \beta-n}(x)$ (3.2) can be put in the form

$$
\begin{aligned}
& F^{(1)}\left(c, D ;-\alpha,-\beta: \frac{-t}{2(x-1)}, \frac{-t}{2(x+1)}\right) \\
= & \sum_{n=0}^{\infty} \frac{(c)_{n}}{(D)_{n}} f_{n}^{\alpha-n, \beta-n}(x) t^{n} .
\end{aligned}
$$

The differential formula for $f_{n}^{\alpha-n, \beta-n}(x)$ is [5]

$$
f_{n}^{\alpha-n, \beta-n}(x)=\frac{(-)^{n}}{2^{n} n !}(1-x)^{-\alpha}(1+x)^{-\beta} D^{n}\left[(1-x)^{\alpha}(1+x)^{\beta}\right] .
$$

Thus comparing (3.3) and (3.4) with (1.1) and (1.2) we get

$$
a_{m}=\frac{(c)_{m}}{(D)_{m}}, \mu(n)=\frac{(-)^{n}}{2^{n} n !}, G(x)=(1-x)^{\alpha}(1+x)^{\beta}
$$

and therefore our theorem gives, after replacing $t$ by $t\left(1-x^{2}\right)$,

$$
\begin{aligned}
& \quad\left[1+\frac{1}{2} t(x+1)\right]^{\alpha}\left[1+\frac{1}{2} t(x-1)\right]^{\beta} \\
& \quad \times F^{(1)}\left(C, D ;-\alpha,-\beta: \frac{t y(x+1)}{2+t(x+1)}, \frac{t y(x-1)}{2+t(x-1)}\right) \\
& =\sum_{n=0}^{\infty}{ }_{2} F_{1}(-n, c ; D:-y) p_{n}^{\alpha-n, \beta-n}(x) t^{n} .
\end{aligned}
$$

Since $p_{n}^{\alpha-n, \beta-n}(x)$ can be reduced to $L_{n}^{\alpha-n}(x)$ by replacing $x$ by $1-2 x / \beta$ and letting $\beta$ tending to infinity, the above result can be put in the following interesting form

$$
\begin{aligned}
& (1+t)^{\alpha} \exp (x t) \varphi_{1}\left(C,-\alpha, D ;-x t y, \frac{t y}{t+1}\right) \\
& =\sum_{n=0}^{\infty}{ }_{2} F_{1}(-n, C ; D ;-y) L_{n}^{\alpha-n}(x)
\end{aligned}
$$

where $\phi_{1}$ is a confluent form of $F^{(1)}$ given by

$$
\phi_{1}(\alpha, \beta, \gamma ; x, y)=\sum_{n=0}^{\infty} \sum_{m=0}^{\infty} \frac{(\alpha)_{m+n}(\beta)_{n}}{(\gamma)_{m+n} m ! n !} x^{m} y^{n}, \quad|x|<1 .
$$

This again reduces to the following result due to Srivastava [6]

$$
\begin{aligned}
& (1+t)^{\alpha} \exp (-y t) \phi_{3}\left(-\alpha, D: \frac{y t}{t+1}, x y t\right) \\
= & \sum_{n=0}^{\infty}\left(\begin{array}{c}
D-1+n \\
n
\end{array}\right)^{-1} L_{n}^{D-1}(y) L_{n}^{\alpha-n}(x) t^{n}
\end{aligned}
$$


where $\phi_{3}$ is a confluent form of $\phi_{1}$. This is obtained by replacing $y$ by $-(y / C)$ in (3.4) and letting $C$ tend to infinity.

4. Generalization of (3.2). The result (3.1) is capable of generalization by the repeated application of the method indicated in proving (3.2). One can easily write it as

$$
\begin{aligned}
& F_{0,0}^{r, 1}\left(\left.\left.|a|\right|_{s}\right|_{s} ;-\alpha,-\beta: \frac{1}{2}(x+1) t, \frac{1}{2}(x-1) t\right) \\
= & \sum_{n=0}^{\infty} \frac{\left(a_{1}\right)_{n} \cdots\left(a_{r}\right)_{n}}{\left(b_{1}\right)_{n} \cdots\left(b_{s}\right)_{n}} p_{n}^{\alpha-n, \beta-n}(x) t^{n}
\end{aligned}
$$

in the notation of Srivastava and Saran [7] for Kampé de Fériet function.

Thus (3.5) can be generalized into

$$
\begin{aligned}
& \quad\left[1+\frac{1}{2} t(x+1)\right]^{\alpha}\left[1+\frac{1}{2} t(x-1)_{x}^{\beta}\right. \\
& \quad \times F_{s, 0}^{r, 1}\left(\mid \begin{array}{l}
|a| r \mid \\
|b| s
\end{array} ;-\alpha,-\beta: \frac{y t(x+1)}{2+t(x+1)}, \frac{y t(x-1)}{2+t(x-1)}\right) \\
& =\sum_{n=0}^{\infty}{ }_{r+1} F_{s}\left(-n, a_{r} ; b_{s}:-y\right) p_{n}^{\alpha-n, \beta-n}(x) t^{n} .
\end{aligned}
$$

\section{REFERENCES}

1. F. Brafman, Some generating functions for Laguerre and Hermite polynomials, Canad. J. Math. 9 (1957), 180-187.

2. L. Carlitz, A bilinear generating function for the Jacobi polynomials, Boll. Un. Math. Italy (3) 18 (1963), 87.

3. S. K. Chatterjea, A bilateral generating function for the Ultraspherical polynomials, Pacific J. Math. 29 (1969), 73-76.

4. E. T. Copson, An Introduction to Theory of Function of a Complex Variable, Oxford University Press, (1935), 226.

5. E. D. Rainville, Special functions, Macmillan Co., New York, 1960.

6. H. M. Srivastava, An extension of the Hille-Hardy formula, Math. Comp. 23 (1969), 310.

7. G. P. Srivastava and S. Saran, A theorem on Kampé de Fériet function, Proc. Camb. Phil. Soc. 64 (1968), 435.

Received April 7, 1970.

Punjabi University

Patiala, (India) 


\section{PACIFIC JOURNAL OF MATHEMATICS}

\section{EDITORS}

\author{
H. SAMELSON \\ Stanford University \\ Stanford, California 94305 \\ Richard Pierce \\ University of Washington \\ Seattle, Washington 98105
}

\author{
J. DugundJI \\ Department of Mathematics \\ University of Southern California \\ Los Angeles, California 90007 \\ RICHARD ARENS \\ University of California \\ Los Angeles, California 9.0024
}

\section{ASSOCIATE EDITORS}

\begin{tabular}{|c|c|}
\hline E. F. BECKENBACH & K. YoshidA \\
\hline \multicolumn{2}{|c|}{ SUPPORTING INSTITUTIONS } \\
\hline UNIVERSITY OF BRITISH COLUMBIA & STANFORD UNIVERSITY \\
\hline CALIFORNIA INSTITUTE OF TECHNOLOGY & UNIVERSITY OF TOKYO \\
\hline UNIVERSITY OF CALIFORNIA & UNIVERSITY OF UTAH \\
\hline MONTANA STATE UNIVERSITY & WASHINGTON STATE UNIVERSITY \\
\hline UNIVERSITY OF NEVADA & UNIVERSITY OF WASHINGTON \\
\hline NEW MEXICO STATE UNIVERSITY & $* \quad * \quad *$ \\
\hline OREGON STATE UNIVERSITY & AMERICAN MATHEMATICAL SOCIETY \\
\hline UNIVERSITY OF OREGON & CHEVRON RESEARCH CORPORATION \\
\hline OSAKA UNIVERSITY & TRW SYSTEMS \\
\hline UNIVERSITY OF SOUTHERN CALIFORNIA & NAVAL WEAPONS CENTER \\
\hline
\end{tabular}

The Supporting Institutions listed above contribute to the cost of publication of this Journal, but they are not owners or publishers and have no responsibility for its content or policies.

Mathematical papers intended for publication in the Pacific Journal of Mathematics should be in typed form or offset-reproduced, (not dittoed), double spaced with large margins. Underline Greek letters in red, German in green, and script in blue. The first paragraph or two must be capable of being used separately as a synopsis of the entire paper. The editorial "we" must not be used in the synopsis, and items of the bibliography should not be cited there unless absolutely necessary, in which case they must be identified by author and Journal, rather than by item number. Manuscripts, in duplicate if possible, may be sent to any one of the four editors. Please classify according to the scheme of Math. Rev. Index to Vol. 39. All other communications to the editors should be addressed to the managing editor, Richard Arens, University of California, Los Angeles, California, 90024.

50 reprints are provided free for each article; additional copies may be obtained at cost in multiples of 50 .

The Pacific Journal of Mathematics is published monthly. Effective with Volume 16 the price per volume (3 numbers) is $\$ 8.00$; single issues, $\$ 3.00$. Special price for current issues to individual faculty members of supporting institutions and to individual members of the American Mathematical Society: $\$ 4.00$ per volume; single issues $\$ 1.50$. Back numbers are available.

Subscriptions, orders for back numbers, and changes of address should be sent to Pacific Journal of Mathematics, 103 Highland Boulevard, Berkeley, California, 94708.

PUBLISHED BY PACIFIC JOURNAL OF MATHEMATICS, A NON-PROFIT CORPORATION

Printed at Kokusai Bunken Insatsusha (Internatıonal Academic Printing Co., Ltd.), 7-17, Fujimi 2-chome, Chiyoda-ku, Tokyo, Japan. 


\section{Pacific Journal of Mathematics}

\section{Vol. 35, No. $3 \quad$ November, 1970}

John D. Arrison and Michael Rich, On nearly commutative degree one algebras . . . 533

Bruce Alan Barnes, Algebras with minimal left ideals which are Hilbert spaces . . . . 537

Robert F. Brown, An elementary proof of the uniqueness of the fixed point index . . . 549

Ronn L. Carpenter, Principal ideals in F-algebras .................... 559

Chen Chung Chang and Yiannis (John) Nicolas Moschovakis, The Suslin-Kleene

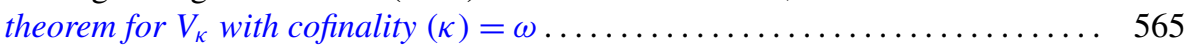

Theodore Seio Chihara, The derived set of the spectrum of a distribution

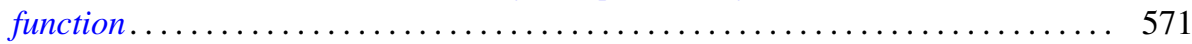

Tae Geun Cho, On the Choquet boundary for a nonclosed subspace of $C(S) \ldots \ldots \quad 575$

Richard Brian Darst, The Lebesgue decomposition, Radon-Nikodym derivative,

conditional expectation, and martingale convergence for lattices of sets .......

David E. Fields, Dimension theory in power series rings . . . . . . . . . . . .

Michael Lawrence Fredman, Congruence formulas obtained by counting

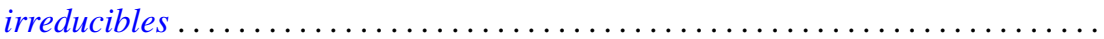

John Eric Gilbert, On the ideal structure of some algebras of analytic functions.....

G. Goss and Giovanni Viglino, Some topological properties weaker than

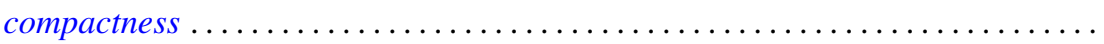

581

601

625

George Grätzer and J. Sichler, On the endomorphism semigroup (and category) of

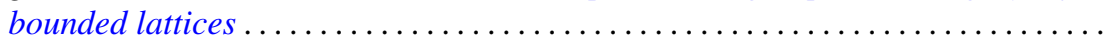

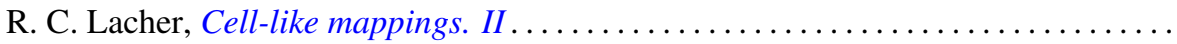

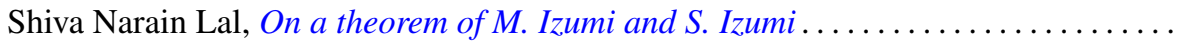

661

Howard Barrow Lambert, Differential mappings on a vector space ...............

Richard G. Levin and Takayuki Tamura, Notes on commutative power joined

semigroups.

Robert Edward Lewand and Kevin Mor McCrimmon, Macdonald's theorem for quadratic Jordan algebras.

J. A. Marti, On some types of completeness in topological vector spaces ....

Walter J. Meyer, Characterization of the Steiner point

717

Saad H. Mohamed, Rings whose homomorphic images are $q$-rings ...

727

Thomas V. O'Brien and William Lawrence Reddy, Each compact orientable surface

of positive genus admits an expansive homeomorphism ...

737

Robert James Plemmons and M. T. West, On the semigroup of binary relations...

743

Calvin R. Putnam, Unbounded inverses of hyponormal operator . .

755

William T. Reid, Some remarks on special disconjugacy criteria for differential

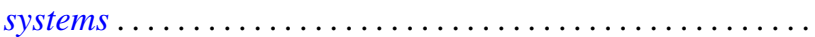

C. Ambrose Rogers, The convex generation of convex Borel sets in euclidean

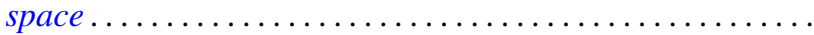

S. Saran, A general theorem for bilinear generating functions .

S. W. Smith, Cone relationships of biorthogonal systems ......

Wolmer Vasconcelos, On commutative endomorphism rings ....

795

Vernon Emil Zander, Products of finitely additive set functions from Orlicz

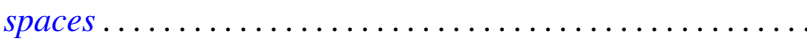

G. Sankaranarayanan and C. Suyambulingom, Correction to: "Some renewal

theorems concerning a sequence of correlated random variables" .

Joseph Zaks, Correction to: "Trivially extending decompositions of $E^{n}$ ”....... 805

Dong Hoon Lee, Correction to: "The adjoint group of Lie groups" ............ 805

James Edward Ward, Correction to: "Two-groups and Jordan algebras". 